\title{
Prevention, identification, and management of post-operative penile implant complications of infection, hematoma, and device malfunction
}

\author{
Timothy K. O'Rourke Jr ${ }^{1}$, Alexander Erbella ${ }^{1}$, Yu Zhang ${ }^{1}$, Matthew S. Wosnitzer ${ }^{1,2}$ \\ ${ }^{1}$ Quinnipiac University Frank H. Netter MD School of Medicine, Hamden, CT, USA; ${ }^{2}$ Yale New Haven Health-Northeast Medical Group \\ Urology/Male Reproductive Medicine and Surgery, Fairfield, CT, USA \\ Contributions: (I) Conception and design: MS Wosnitzer, TK O’Rourke Jr; (II) Administrative support: MS Wosnitzer; (III) Provision of study \\ material or patients: None; (IV) Collection and assembly of data: All authors; (V) Data analysis and interpretation: All authors; (VI) Manuscript \\ writing: All authors; (VII) Final approval of manuscript: All authors. \\ Correspondence to: Matthew S. Wosnitzer, MD. Yale New Haven Health-Northeast Medical Group Urology/Male Reproductive Medicine and \\ Surgery, 425 Post Road, Fairfield, CT 06824, USA. Email: matthew.wosnitzer@ynhh.org.
}

\begin{abstract}
Penile prosthesis implant surgery is an effective management approach for a number of urological conditions, including medication refractory erectile dysfunction (ED). Complications encountered post-operatively include infection, bleeding/hematoma, and device malfunction. Since the 1970s, modifications to these devices have reduced complication rates through improvement in antisepsis and design using antibiotic coatings, kink-resistant tubing, lock-out valves to prevent autoinflation, and modified reservoir shapes. Device survival and complication rates have been investigated predominately by retrospective database-derived studies. This review article focuses on the identification and management of post-operative complications following penile prosthetic and implant surgery. Etiology for ED, surgical technique, and prosthesis type are variable among studies. The most common post-operative complications of infection, bleeding, and device malfunction may be minimized by adherence to consistent technique and standard protocol. Novel antibiotic coatings and standard antibiotic regimen may reduce infection rates. Meticulous hemostasis and intraoperative testing of devices may further reduce need for revision surgery. Additional prospective studies with consistent reporting of outcomes and comparison of surgical approach and prosthesis type in patients with variable ED etiology would be beneficial.
\end{abstract}

Keywords: Penile implant; complications; infection; hematoma; device malfunction

Submitted Feb 27, 2017. Accepted for publication May 05, 2017.

doi: $10.21037 /$ tau.2017.06.07

View this article at: http://dx.doi.org/10.21037/tau.2017.06.07

\section{Introduction}

The first penile implant was introduced by Lash et al. in 1964 as part of a novel surgical reconstruction for Peyronie's disease (1). Dramatic increase in penile prosthesis implantation occurred in the 1970's, specifically for men with erectile dysfunction (ED). Scott et al. introduced the world's first inflatable penile prosthesis (IPP) in 1973 (2). Although prosthetic implants have changed over the years, original design principles remain largely intact with continued improvement to minimize perioperative complications in two or three-piece designs (3).

Indications for penile prostheses vary. For men with ED of any etiology, prostheses become a viable surgical option when less invasive measures fail such as phosphodiesterase-5 inhibitors (PDE5Is) and intracavernosal injection therapy (4-6). When such interventions are undesirable or unsuccessful, penile prosthesis surgery is considered (6). Before proceeding, informed consent includes discussion of risks such as infection, bleeding, and device malfunction. The incidence, identification, and management, of such post- 
operative complications will be the subject of this review article. In addition, variables which may affect outcomes including surgeon technique and volume will be discussed.

\section{Methods}

PubMed (PMID) was queried for MeSH terms "penile prosthesis" and "complication, postoperative" for all English-language articles without time restriction through January 2017. An additional query included the term "penile prosthesis complications" with pertinent studies referencing post-operative complications including infection, hematoma, and device malfunction. Studies selected for inclusion in this review article include the largest studies with emphasis on prospective design. Recent articles were given preference to reflect continued development and enhancements in penile prosthesis design, in an effort to provide a clinically applicable perspective.

\section{Results}

The initial PubMed (PMID) search yielded 944 articles, of which 384 were deemed pertinent with emphasis placed on identification and management of post-operative infection, hematoma, and device malfunction. Post-operative infection was captured in 4 prospective and 8 retrospective studies. Nine retrospective studies were included in the review of post-operative hematoma. Given the broad nature of the category device malfunction, 17 total studies were included in this review, 3 of which were prospective in nature. A paucity of prospective, randomized studies was identified in the literature relating to penile prostheses.

\section{Post-operative infection}

Despite changes in prosthetic devices and surgical technique in recent years, infection remains a major penile prosthesis post-operative complication. Early trials often involved very small population sizes (7-9). Herein we have described rates of infection and revision surgery due to infection from some of the largest and most recent studies (Table 1). Most studies utilize IPPs while others describe semi-rigid devices. Additionally, many of these devices use antibiotic coatings released by device manufacturers in the early 2000s which continue to be widely used in penile prostheses today (22). Studies were categorized and analyzed by design (prospective $v s$. retrospective). Rates of infection or of revision surgery due to infection range between $0.46 \%$ and
$5.3 \%$ (15). In these studies, infection rates vary depending on antibiotic coatings, surgical technique, or comorbidities such as diabetes. Further, use of intraoperative IV antibiotic, antibiotic solution, and postoperative antibiotics are variable among studies. Because there are no universal guidelines for perioperative antibiotic use, there is significant variability among general urologists and urologists specializing in penile prosthesis insertion (23). The senior author utilizes intravenous vancomycin and gentamicin administered immediately preoperatively, vancomycin/gentamicin solution intraoperatively, and ciprofloxacin postoperatively. The AUA antimicrobial prophylaxis guidelines recommend judicious use of postoperative antibiotics for a period up to 24 hours (24-26). Consultation with the infectious disease department based on hospital-specific infection history may be valuable in selection of antibiotics. Strict adherence to antisepsis, re-gloving, and ensuring limited traffic in and out of the operating room may prevent inoculation of bacteria in the operative field.

\section{Identification}

Patients with post-operative infection may present with pain, fever, and/or tachycardia, with elevated white blood cell count and, occasionally, frank purulent discharge, erythema, or areas of fluctuance at the surgical site (27). Patients may be initially assessed for sepsis through the quickSOFA [Sequential (Sepsis-related) Organ Failure Assessment] criteria, worked up accordingly, and stabilized (28). Infections are a feared complication of penile prosthesis and implant surgery requiring prompt recognition and treatment. The time course can vary widely with postoperative infection diagnosed within 7 months, between 7 to 12 months, and later than 5 years in $56 \%, 36 \%$, and $2.6 \%$ of patients, respectively (29). While diabetic patients demonstrate elevated post-operative infection risk (16), all patients should be assessed in the days and initial weeks postoperatively.

\section{Prospective studies}

The prospective studies of IPP outcomes reported infection rates between $1.67 \%$ and $3 \%(11,21)$. However, two larger studies reported rates below $2 \%(11,18)$. While these studies do not have the same limitations as the retrospective studies (see next section), the rates are relatively comparable. Similar trends can be found throughout these studies including the 
Table 1 Studies examining the identification and management of post-operative infection

\begin{tabular}{|c|c|c|c|c|c|c|c|c|c|}
\hline Author & Year & Study design & $\begin{array}{c}\text { Sample size } \\
\text { (n) }\end{array}$ & $\begin{array}{l}\text { Maximum } \\
\text { follow-up } \\
\text { (years) }\end{array}$ & $\begin{array}{c}\text { Rate of } \\
\text { infection (\%) }\end{array}$ & $\begin{array}{l}\text { Reoperation due } \\
\text { to infection (\%) }\end{array}$ & $\begin{array}{c}\text { Preoperative } \\
\text { antibiotics (IV) }\end{array}$ & $\begin{array}{c}\text { Intraoperative } \\
\text { antibiotics } \\
\text { (irrigation) }\end{array}$ & $\begin{array}{c}\text { Postoperative } \\
\text { antibiotics }\end{array}$ \\
\hline $\begin{array}{l}\text { Antonini } \\
\text { et al. (11) }\end{array}$ & 2016 & Prospective & 180 & 1 & NR & 1.67 & Cefazolin & NR & $\begin{array}{l}\text { Cefazolin, } \\
\text { gentamycin }\end{array}$ \\
\hline $\begin{array}{l}\text { Mirheydar } \\
\text { et al. (13) }\end{array}$ & 2016 & Retrospective & 7,666 & 15 & NR & 3.8 & NR & NR & NR \\
\hline $\begin{array}{l}\text { Grewal } \\
\text { et al. (14) }\end{array}$ & 2014 & Retrospective & 2,263 & 4 & NR & 3.6 & NR & NR & NR \\
\hline $\begin{array}{l}\text { Carson } \\
\text { et al. (17) }\end{array}$ & 2011 & Retrospective & 39,005 & 7.7 & NR & $1.1-2.5$ & NR & NR & NR \\
\hline $\begin{array}{l}\text { Wilson } \\
\text { et al. (18) }\end{array}$ & 2007 & Prospective & 467 & 1 & 1.9 & NR & $\begin{array}{l}2^{\text {nd }} \text { generation } \\
\text { cephalosporin }\end{array}$ & $\begin{array}{c}\text { Non-specific } \\
\text { antibiotic }\end{array}$ & Quinolone \\
\hline $\begin{array}{l}\text { Wolter } \\
\text { et al. (19) }\end{array}$ & 2004 & Retrospective & 2,839 & 1 & $1.06-2.07$ & NR & NR & NR & NR \\
\hline $\begin{array}{l}\text { Carson } \\
\text { et al. (20) }\end{array}$ & 2004 & Retrospective & 4,205 & 1 & $0.90-2.35$ & NR & NR & NR & $N R$ \\
\hline $\begin{array}{l}\text { Mulhall } \\
\text { et al. (21) }\end{array}$ & 2001 & Prospective & 79 & 1.5 & $2.0-3.0$ & NR & $\begin{array}{l}\text { Gentamicin, } \\
\text { ampicillin }\end{array}$ & NR & Ciprofloxacin \\
\hline
\end{tabular}

NR, not reported; TBD, to be determined.

effectiveness of antibiotic coatings to reduce infection rates.

In 2001, Mulhall and Bloom conducted a prospective trial of 79 IPPs implanted by a single surgeon between 1996 and 1998 (21). This was the first study identifying similarities between in-patient and out-patient outcomes. The authors identified no differences in blood loss, narcotic use, recovery time, or complications between the two groups (Student's $t$-test) and concluded that out-patient surgery was a viable option for patients seeking these procedures. The authors used transverse scrotal approach and the American Medical Systems (AMS) Ambicor ${ }^{\text {TM }}$ IPP (Boston Scientific, Marlborough, MA, USA) and the Mentor Alpha-1 IPP (Mentor, Santa Barbara, CA, USA). A single infection was reported for each group, leading to infection rates of $2 \%$ and $3 \%$ for out-patient and in-patient procedures, respectively. Follow-up for the out-patient group was a median of 8 months versus a median of 18 months for the in-patient group. Its prospective nature is a major benefit while limitations include relatively small patient population and short-term follow-up. Despite this, the infection rates reported here are similar to other published studies including the retrospective studies to be discussed.

In 2007, Wilson et al. conducted a prospective study using a historical control versus a group of 467 men implanted with the AMS $700^{\mathrm{TM}}$ Controlled Expansion (CX) IPP with InhibiZone ${ }^{\mathrm{TM}}$ between 2001 and 2004 with 1-year follow-up (18). The authors separated infection rates between several subgroups, including revisions with and without washout and virgin implants in diabetics and nondiabetics. The overall infection rate was $1.9 \%$. Interestingly, no infections occurred among the 223 virgin implants in nondiabetic men. The highest infection rate occurred in the revision without washout group at a rate of $10.3 \%$. This was the only group that did not show any reduction between the coated IPP and non-coated IPPs (two-sided exact test, $\mathrm{P}=1.0$ ). The infection rates listed 
in Table 1 relate to the prospective arm of this study. To our knowledge, this arm alone represents one of the largest populations in prospective studies in peer-reviewed literature. Although the experimental arm of this study is prospective, a limitation is its use of historical controls. The authors originally intended for the control arm to be part of the prospective design, however, cited "ethical considerations" when deciding to eliminate it.

In 2016, Antonini et al. conducted a prospective study of IPPs performed by a single surgeon (11). A minimally invasive infrapubic approach was performed utilizing either the AMS $700^{\mathrm{TM}} \mathrm{CX}$ or the Coloplast Titan ${ }^{\circledR}$ OneTouch Release (OTR). This study included 180 men followed over 12 months and compared satisfaction, efficacy, and complication rates between two groups with differing etiologies for ED. The first group was made up of patients with diabetes/metabolic syndrome and the second with men with history of radical prostatectomy. No statistical differences were identified between the groups in International Index of Erectile Function-5 (IIEF-5) and Erectile Dysfunction Inventory of Treatment Satisfaction scores post-implantation (one-tailed $t$-test, $\mathrm{P}=0.65$ and 0.55 , respectively) or post-operative infectious complications $(\mathrm{P}=0.11)$. Overall, $3(1.67 \%)$ patients underwent exploration due to infection. These results are contrasted by those of the Mulcahy and Carson retrospective sub-analysis in 2011 demonstrating higher rates of revision due to infection in diabetic men (16).

Also in 2016, Henry et al. reported initial results from a large, prospective, multicenter trial examining penile implant outcomes (12). Their study included 1,019 patients at 11 sites in North America, with follow-up planned in 5 years. So far, results focus on other aspects of penile implantation such as etiology, approach, device used, and operative time. Outcomes and complications, such as infection, will be reported once additional data is collected. The results of this study are promising when considering its scale and prospective nature. Once completed, it will be the largest prospective, peer-reviewed study reporting complication rates of penile prostheses.

\section{Retrospective studies}

In early 2004, Carson performed a retrospective analysis of 4,205 men undergoing IPP implantation with AMS $700^{\mathrm{TM}}$ with and without the InhibiZone ${ }^{\mathrm{TM}}$ rifampin and minocycline coating (20). One year following implantation, infection rate for the antibiotic coated group was $0.90 \%$ and the uncoated group was $2.35 \%$. This study along with others have concluded that antibiotic coating on penile prosthetic devices significantly reduced infection rates (Log-rank, $\mathrm{P}=0.0002$ ) (20). While this study included a large population of subjects, limitations include retrospective nature and use of voluntary manufacturer-based database. Given the voluntary nature of this database, underreporting of complications may lead to inaccurate recording of complications.

In late 2004, Wolter and Hellstrom performed a retrospective comparison of IPPs from different device manufacturers than the Carson study. This study describes the use of the Coloplast Titan ${ }^{\circledR}$ IPP with polyvinylpyrrolidone coating (Coloplast, Minneapolis, MN, USA) and the non-coated Alpha-1 IPP (19). The Titan ${ }^{\circledR}$ coating was designed to absorb antibiotic immersions and reduce bacterial adherence thereby decreasing infection rates. Over a 1-year period, 2,357 Titan $^{\circledR}$ IPPs were implanted versus 482 Alpha-1 IPPs. Infection rates were $1.06 \%$ and $2.07 \%$ respectively (one-sided chi-square, $\mathrm{P}=0.033$ ). This was an early, relatively large, retrospective study analyzing the effectiveness of antibiotic coated IPPs. Similar studies prior to this typically utilized smaller populations or devices which are rarely used today. Limitations in this study are similar to other articles including the use of a manufacturer-based database (20).

In 2011, Carson, Mulcahy, and Harsch expanded on the retrospective study performed by Carson in 2004 (20). This large retrospective analysis of 39,005 analyzed men who underwent IPP implantation with a maximum follow-up of 7.7 years (17). Similar to their prior study, the authors separated their study population into two groups, men receiving AMS 700 IPP with minocycline and rifampin coating and those who received non-coated IPPs. However, this study reports the rate of revision surgery due to infection whereas the 2004 Carson study reported overall rates of infection. Of the 35,737 men who received implantation with the coated IPP, $1.1 \%$ underwent revision surgery due to infection. Only 3,268 men received a non-impregnated IPP and their revision rate was more than double that of the coated group at 2.5\% (Log-rank, $\mathrm{P}<0.0001)$. These rates are only slightly higher than those reported in Carson's smaller study in 2004 (20). However, because this study reports rates of revision due to infection and not rates of overall infection, the actual rates of infection in this population may be even larger. Furthermore, the much larger antibiotic impregnated group had an average follow-up 3 years shorter than the non-impregnated 
group. The authors recognize that longer follow-up may identify an increased complication rate in this group. Additional limitations to this study include its retrospective nature and their use of a voluntary registry (20). However, to our knowledge, this is the largest study examining penile implantation complication rates to date.

Additionally in 2011, Mulcahy and Carson published a subgroup analysis reporting the revision rates due to infection in 6,695 diabetic men utilizing the data from their large retrospective study described previously (16). Diabetic men who received an antibiotic coated IPP experienced a revision rate due to infection of $1.47 \%$ and men receiving non-coated IPPs had a rate of $4.17 \%$ (chi-square, $\mathrm{P}<0.0001$ ). Overall, total revisions for infection took place in $1.72 \%$ of diabetic men versus $1.26 \%$ of men without diabetes ( $\log$-rank, $\mathrm{P}=0.0052)$. This is one of the largest IPP studies describing infection rates in diabetic men, however, the same limitations apply to this study as other similar retrospective publications.

In 2012, Eid et al. published a retrospective analysis of a series of 2,347 implants performed by a single surgeon between 2002 and 2011 (15). Non-coated IPPs were used in 2002, followed by antibiotic coated IPPs in 2003 and the addition of the "no touch" technique in 2006. The devices used included IPPs from Mentor, Coloplast, and AMS. Infection rates declined through the years as devices and techniques improved. Initially, 132 patients received a noncoated IPP with an infection rate of $5.3 \%$. Subsequently, 704 patients received a coated IPP with an infection rate of $2 \%$ (Fisher's exact test, $\mathrm{P}=0.035$ ). Finally, 1,511 patients received coated IPPs with the "no touch" technique with an associated infection rate of $0.46 \%$ (Fisher's exact test, $\mathrm{P}<0.0001)$. No differences were observed in infection rates between the device manufacturers. To our knowledge, this study reports one of the lowest infection rates in the literature through the combined use of antibiotic coated IPPs and surgical technique. While the study had a single surgeon with standardized operative technique, it is difficult to predict whether these results can be generalized to other surgeons with different techniques at different institutions.

In 2014, Grewal et al. published a retrospective study of 2,263 men receiving either a semi-rigid prosthesis or IPP with a follow-up up to 4 years (14). CPT and ICD-9 codes from the Healthcare Cost and Utilization Project database in California were analyzed. Revision rates due to infection for the 439 men receiving semi-rigid implants and the 1,824 men receiving IPPs were $4.5 \%$ and $3.23 \%$, respectfully. There was no statistical difference between these groups (Kaplan-Meier analysis, $\mathrm{P}=0$.94) leading the authors to conclude that there was no difference in infection rates between device types. Unfortunately, the precise type of device used in these patients was not indicated. Lack of information regarding specific devices or antibiotic coating is a major limitation to this study. It may be reasonable to consider that the majority of these men received antibiotic coated devices due to the timing of surgery, between 2006 and 2009, well after antibiotic coatings were in wide use. Taken together, the overall revision rate for infection in the study was $3.6 \%$. This rate is slightly higher than the rates reported in the Carson and Mulcahy studies in earlier years $(16,17)$, however, these findings more closely approximate rates described by Mirheydar et al., using a similar database (13).

In 2016, Mirheydar et al. analyzed the charts of over 7,000 patients in the California with a maximum follow-up of 13 years (13). Of 904 revision surgeries, 295 were due to infection-a $3.84 \%$ reoperation rate due to infection. The authors utilized a different database (California Office of Statewide Health Planning and Development) and longer time interval (1995 through 2010) than Grewal et al. (14). Interestingly, of the 904 men who underwent revision surgery for any reason, 264 (29.2\%) did so at different hospitals from where their initial implantation occurred. The authors suggest that complication rates reported in the literature may be lower than actual rates in the general population. This is particularly relevant for many single surgeon or small multi-institutional studies. However, this may be less applicable to the large, state-wide registry studies such as those performed by Grewal et al. (14) and Onyeji et al. (10) or voluntary manufacturer registries as used by Carson et al. (17). Further, the reoperation rate due to infection that Mirheydar et al. reported is higher (3.84\%) than the rates reported in the Onyeji et al. $(2.3 \%)$ and the Carson $e$ al. study $(1.1-2.5 \%)$ but similar to the rate in the Grewal et al. study $(3.23 \%)(10,14,17)$. Both the Grewal et al. and the Mirheydar et al. studies utilized California based databases. Their similar rates may indicate that patients in California have a slightly higher rate of revision due to infection than the national average or other particular regions. Alternatively, this may indicate that these studies did indeed capture patients who received revision surgery at institutions different than their original surgery. This consideration may be supported by the lower revision rates observed in the Onyeji et al. study (10).

In a recent study, Onyeji et al. investigated the impact of surgeon case volume on reoperation rates after IPP surgery through a large retrospective study examining data 
pertaining to 14,969 patients from 1996 to 2014 in the New York Statewide Planning and Research Cooperative System Database (SPARCS) (10). The overall rate of reoperation due to infection was $2.3 \%(\mathrm{~N}=343)$. Among infections, 217 occurred prior to the routine implementation of antibiotic coated prostheses leading to a rate of $4.2 \%$ in these patients. Once antibiotic coatings were widely used, the infection rate dropped to $1.5 \%(\mathrm{~N}=126)$. Further, authors found that surgeons with higher annual case volumes experienced lower rates of reoperation due to infection (Cox regression analysis, $\mathrm{P}<0.001-0.01$ ). The rates of infection in this study are lower than those in the studies which used California databases. Unfortunately, due to the structure of the database utilized, patients who received revision surgery in other states were not captured, and as such the true revision rates may be higher than reported. Therefore, actual rates of revision due to infection may be closer to the California studies, greater than this New York study or those performed by Carson et al. $(13,14,17,20)$ because their database is limited to manufacturer databases comprised of voluntary reporting. Overall, these issues reflect the limitations of retrospective studies which are vulnerable to selection bias.

\section{Management}

Initial management principles in patients presenting with signs of infection include assessing and stabilizing hemodynamic parameters. Patients presenting with signs of sepsis should receive prompt, standardized treatment including fluid resuscitation and systemic antibiotics. Stabilized patients with obvious signs of infected penile prosthesis generally require explantation and reimplantation of the prosthesis. Historically, a penile prosthesis would be explanted with delayed reimplantation. Due to the increased rates of corporal scarring and fibrosis that would invariably occur during this period of time prior to reimplantation, the prosthetic salvage procedure as described by Mulcahy et al. with device removal and replacement in the same operative setting gained popularity. Judicious wash-out of the affected area was implemented with significantly improved outcomes. This important advancement in the treatment of prosthesis infections is now the standard of care for management $(30,31)$.

\section{Bleeding and hematoma}

Hematoma formation in the post-operative setting is a potential complication for many different procedures, and they may contribute to post-operative complications following IPP placement. Hematomas typically develop in the scrotum, a dependent organ that provides ample expansion for blood and other fluid to collect. Additionally, hematoma may also form secondary to vascular or bladder injury during reservoir placement, however, the majority of such injuries would be recognized intraoperatively. The corporotomies required for penile prosthesis surgery can be a source of significant bleeding. Utilizing stay sutures and running horizontal mattress sutures during closure of the corporotomies may mitigate some risk of hematoma formation through hemostasis (32). Even when hematomas do form, they generally do not require re-exploration and do not result in device failure. Hematomas can typically be managed conservatively in many cases (33-35). In one study of revision surgeries following penile prosthesis implantation, only 2 of 200 subjects required revision due to the presence of scrotal hematoma (1\%). Revision was predominantly secondary to mechanical device failure $(65 \%)$ and erosion (10\%) or infection (9\%) (36). While hematoma formation is not as devastating relative to infection and device failure, it may be problematic in the post-operative course, presenting with scrotal pain, decreased patient comfort, and an increased length of observation or repeat office visits $(34,37)$.

\section{Time of onset}

Few studies in the literature explicitly address the time of onset for hematoma formation. Pozza and colleagues examined hematoma formation in the immediate postoperative period (post-operative day one) for semi-rigid and inflatable prostheses with and without scrotal drainage (34). Another study reviewed delayed hematoma formation defined as occurrence after the fifth post-operative day (38). This study purported to be the only focusing on delayed hematoma formation. However, without a universal definition of early versus delayed hematoma formation, the data from each study in penile prosthesis literature must be analyzed to determine the timing of hematoma. Scrotal hematoma will usually become evident in the immediate post-operative period when adequate hemostasis is not achieved intraoperatively.

\section{Incidence}

The overall incidence of hematoma formation following 
penile prosthesis or implant surgery ranges from $0.2 \%$ to $3.6 \%$ (Table 2). In one study, a single surgeon implanted 500 prostheses between the years 1984 to 2013, with 138 of the total 500 being inflatable prostheses. With the first 50 prostheses, the surgical team did not use drainage systems and subsequently encountered 11 cases (22\%) of scrotal hematoma on post-operative day one. Eight of the 11 cases required needle aspiration, and all 11 cases required extended hospitalization for observation. In the remainder of the hydraulic cases, the surgical team routinely used scrotal drainage and observed only 5 cases $(5.6 \%)$ of scrotal hematoma formation. Four out of the 5 cases encountered while using drainage were managed with evacuation using the intact drainage system, and only 1 case out of the total 5 cases required repeated aspiration and cylinder inflation to stop the bleeding (34). If the $22 \%$ complication outlier is excluded, the range of hematoma formation in the literature is $0.2 \%$ to $5.6 \%$. Risk factors for hematoma development include lack of meticulous hemostasis intraoperatively, nonvascular causes of ED with well vascularized corpora, and revision cases where the capsule has developed neovascularity $(37,45)$.

\section{Prevention}

Several methods to decrease the risk of bleeding and hematoma formation have been described. Some surgeons utilize a watertight closure for corporotomies in order to decrease post-operative bleeding risk using multiple interrupted horizontal mattress sutures (32). Application of compressive dressings (i.e., Coban wrap, scrotal support, fluff gauze) is another noninvasive technique to decrease bleeding risk. Complicated non-sticky compressive "mummy wrap" dressing techniques provide scrotal compression without the pain associated with adhesive dressings (46). With IPPs, partial cylinder inflation has a role in decreasing bleeding as well $(37,39,40,44)$. A combination of postoperative compressive dressing use in conjunction with device inflation has been employed in studies in attempt to achieve hemostasis and prevent hematomas $(44,47)$. In one study, compressive dressing use alone resulted in a hematoma complication rate of $2.9 \%$. The addition of closed drainage and partial device inflation to compressive dressing use led to a statistically significant decrease in hematoma complication rate to $0.9 \%(\mathrm{P}=0.009)(44)$.

Closed drainage use has been a topic of debate. Critics of closed drainage systems cite the increased infection rates from non-urologic procedures as evidence for objection to their use in routine penile prosthesis post-operative care $(45,48)$. Further closed drainage systems are more invasive, require removal, and generally prolong hospital stay and may prevent same day discharge. Proponents of closed drainage use argue that closed drainage decreases postoperative hematoma complication rates without changing infection rates (44). Sadeghi-Nejad and colleagues reviewed the data from 425 primary three-piece IPP implantations; their subject population had a hematoma complication rate of $0.7 \%$ with an infection rate of $3.3 \%$. The rate of infection was comparable to the infection rates reported by other contemporary groups not using closed drainage as a part of their post-operative care (37). Critics of these findings cite the lack of a control group for their study. Without a prospective randomized controlled trial, the evidence for the benefits and risks of drain use remains inconclusive (45).

\section{Management}

Post-operative scrotal hematoma in the setting of penile prosthesis implantation is often managed expectantly without further surgical intervention. Conservative management includes a combination of bed rest, scrotal elevation, compression dressing, ice application, and antibiotics $(38,45)$. In one large retrospective study of 955 penile prosthesis implantations, Chung and colleagues reported that penoscrotal bruising was a common occurrence without quantification of frequency, but they did report that none of the hematomas required surgical intervention (33). Several other studies support the success of conservative management for post-operative scrotal hematomas $(34,35,40)$. Incision and evacuation procedures are inherently invasive and increase infection risk in the post-operative period (37). Garber and colleagues assert that conservative management can be employed when the surgical site is intact. In their retrospective study of 600 patients who received the Coloplast Titan ${ }^{\circledR}$ OTR, three cases of significant post-operative hematoma were identified. These patients presented with swelling of the surgical sites more than 5 days post-surgery, and the extent of the hematomas were confirmed by computed tomography (CT) scan. These patients underwent wound exploration with surgical evacuation, antibiotic washout, and parenteral antibiotics with resolution of hematoma (38). Levine et al. also reported successful surgical evacuation of a post-operative hematoma without further complications (41). Because of the retrospective models and small sample sizes, the evidence to support 
Table 2 Studies examining the identification and management of post-operative hematoma

\begin{tabular}{|c|c|c|c|c|c|c|c|}
\hline Author & Year & Study design & $\begin{array}{l}\text { Sample } \\
\text { size }(n)\end{array}$ & Prosthesis model (s) & Hematoma rate & Management & $\begin{array}{l}\text { Revision } \\
\text { rate due to } \\
\text { hematoma }\end{array}$ \\
\hline $\begin{array}{l}\text { Pozza et al. } \\
\text { (34) }\end{array}$ & 2015 & Retrospective & 500 & 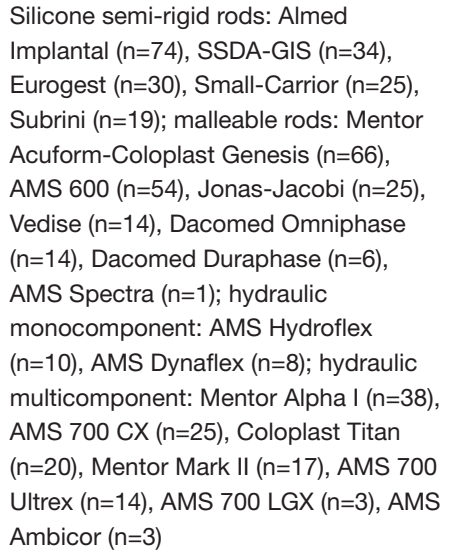 & $\begin{array}{l}\text { Semi-rigid prostheses: } \\
2 / 500(0.4 \%) \text {; hydraulic } \\
\text { prostheses (without } \\
\text { drainage): } 11 / 50(22 \%) ; \\
\text { hydraulic prostheses (with } \\
\text { scrotal drainage): } 5 / 89-90 \\
(5.6 \%) ; \text { [Overall } 18 / 500 \\
(3.6 \%)]\end{array}$ & $\begin{array}{l}\text { Semi-rigid prosthesis: } \\
2 \text { more days of } \\
\text { hospitalization and } \\
\text { medical treatment } \\
\text { Hydraulic prostheses } \\
\text { (without drainage): } \\
\text { observation } \pm \text { needle } \\
\text { aspiration and medical } \\
\text { treatment; hydraulic } \\
\text { prostheses (with } \\
\text { drainage): evacuation } \\
\text { using the tubing of } \\
\text { the drainage system; } \\
1 \text { case required } \\
\text { repeated aspirations }\end{array}$ & $0.2 \% *$ \\
\hline $\begin{array}{l}\text { Garber } \\
\text { et al. (38) }\end{array}$ & 2015 & Retrospective & 600 & Coloplast Titan IPP with OTR pump & $0.5 \%$ ** & $\begin{array}{l}\text { Hospital admission, } \\
\text { intravenous } \\
\text { antibiotics, evacuation } \\
\text { of hematoma, } \\
\text { antibiotic washout }\end{array}$ & $0 \%$ \\
\hline $\begin{array}{l}\text { Natali } \\
\text { et al. (39) }\end{array}$ & 2008 & Retrospective & 200 & $\begin{array}{l}\text { AMS } 700 \text { CX }(n=62) \text {, AMS Ambicor } \\
(n=98) \text {, AMS } 600-650(n=40)\end{array}$ & $2.5 \%$ & - & NR \\
\hline $\begin{array}{l}\text { Sadeghi- } \\
\text { Nejad et al. } \\
\text { (37) }\end{array}$ & 2005 & Retrospective & 425 & Mental Alpha 1, AMS 700 & $0.7 \%$ & - & NR \\
\hline $\begin{array}{l}\text { Minervini } \\
\text { et al. (40) }\end{array}$ & 2005 & Retrospective & 504 & $\begin{array}{l}\text { Malleable: Acu-Form Mentor }(n=256) \text {, } \\
\text { Small-Carrion }(n=77) \text {, AMS 600-650 } \\
(n=52) \text {, Finney }(n=4) \text {, Jonas }(n=4) \text {; self- } \\
\text { contained inflatable: AMS Hydroflex } \\
(n=21) \text {, AMS Dynaflex }(n=8) \text {, Flexiflate } \\
(n=1) \text {; three-piece inflatable: AMS } 700 \\
(n=53) \text {, Mentor Alpha } 1(n=28)\end{array}$ & $2 \%$ & $\begin{array}{l}\text { Conservative } \\
\text { management without } \\
\text { drainage }\end{array}$ & $0 \%$ \\
\hline $\begin{array}{l}\text { Carson } \\
\text { et al. (42) }\end{array}$ & 2000 & Retrospective & 372 & AMS $700 \mathrm{CX}$ & $1.8 \%$ & - & $0 \%$ \\
\hline $\begin{array}{l}\text { Holloway } \\
\text { et al. (35) }\end{array}$ & 1997 & Retrospective & 145 & AMS 700 Ultrex, AMS 700 Ultrex Plus & $2.8 \%$ & None & $0 \%$ \\
\hline $\begin{array}{l}\text { Goldstein } \\
\text { et al. (43) }\end{array}$ & 1997 & Retrospective & 434 & Mentor Alpha 1 & $0.2 \%$ & - & NR \\
\hline $\begin{array}{l}\text { Wilson } \\
\text { et al. (44) }\end{array}$ & 1996 & $\begin{array}{l}\text { Case series } \\
\text { (abstract) }\end{array}$ & 917 & $\begin{array}{l}\text { AMS } 700 \text { Ultrex }(n=73) \text {, AMS } 700 \text { CX } \\
(n=134), \text { Mentor Alpha I }(n=710)\end{array}$ & $\begin{array}{l}\text { Pressure dressing arm: } \\
4 / 136 \text { (2.9\%); pressure } \\
\text { dressing and closed } \\
\text { drainage arm: } 8 / 225(3.6 \%) ; \\
\text { pressure dressing, closed } \\
\text { drainage, and partial } \\
\text { inflation of the cylinders } \\
\text { arm: } 5 / 555(0.9 \%) ; \text { [overall: } \\
17 / 917(1.8 \%) \text { ] }\end{array}$ & - & NR \\
\hline
\end{tabular}

\footnotetext{
*, one patient with hematoma had penile prosthesis explanation 2 months post-operatively due to infection developing following repeated scrotal aspiration; ${ }^{* *}$, this study sought to evaluate delayed formation of post-operative hematomas defined as occurring $>5$ days post-operatively; the authors did not investigate the frequency of immediate hematoma formation. NR, not reported.
} 
surgical management of hematomas is insufficient.

\section{Device malfunction}

Post-operative complication from device malfunction can occur for a variety of reasons. The most common malfunctions described include leakage (reservoir, tubing, or cavernosal cylinders themselves), autoinflation of the prosthesis, and pump malfunction (27). Other less common device malfunction can include and/or lead to urethral erosion, reservoir herniation, reservoir erosion into bowel or bladder, ectopic reservoir location, perforation of the glans, iliac vein compression, and vascular injury, among others $(17,27,49,50)$. These mechanical aberrations with consequences to adjacent anatomy have been the focus of improvements in the design of implantable penile devices, and dramatic advances have been observed in the last several decades. These include the development of kink-resistant tubing, lock-out valves to prevent autoinflation of the cylinders, modifications to the size and shape of the reservoir in three-piece inflatable designs to facilitate placement, and antibiotic-coated or impregnated devices $(46,50,51)$. The Boston Scientific AMS Ambicor ${ }^{\mathrm{TM}}$ two-piece prosthesis has been designed to emulate the overall functionality of a three-piece design but without a fluid reservoir which may be beneficial in avoiding complications associated with reservoir placement especially in patients with challenging pelvic anatomy (52). Table 3 outlines some more recent studies describing complications related to device malfunction. The rates of failure-free device survival reported in contemporary studies will be reviewed.

\section{Identification}

Device malfunction can be a frustrating and potentially devastating complication of penile prosthesis implantation. Patients may present with a variety of issues depending on the type and degree of malfunction present. Device malfunction encompasses complications with prosthesis tubing, cylinders, reservoir, and pump, including leaks or autoinflation (51). Patients may present with specific symptoms pertaining to the specific device malfunction. For example, a patient with a device leak may notice impairment in erection due to damage in the reservoir, connection tubing, or cylinders. Occasionally, autoinflation may occur through capsular formation around the prosthesis leading to increased pressure generation exerting external force on the device. A kink that forms in the tubing, although rare today given the focus on design improvements, will lead to improper inflation of the device. The most common type of device malfunction is fluid loss (Table 3) $(33,43,54,58,61)$.

Mechanical function of implanted prostheses is expected to decline over time, with mechanical survival rates determined by one study to be $97.6 \%, 93.2 \%$, and $78.2 \%$ at 3,5, and 10 years, respectively. Specifically, as presented in the table, among 82 patients with mechanical failure at 82 months of follow-up, cylinder leakage was identified in 57 , reservoir tear in 10, connector tube leakage in 8 , and pump failure in 4 patients. The three remaining patients refused revision and therefore etiology of mechanical failure was not elucidated (54). Another study found prosthesis survival rates of $90.8 \%(95 \%$ CI, 76.2-92.9) at 5 years and $85.0 \%$ (95\% CI, 74.5-88.5) at 10 years (33). In a study published by Carson et al. in 2000, 5-year prosthesis survival rates for mechanical failure and all causes were, respectively, $86.2 \%$ and $78.5 \%$ (42). Wilson et al. reported 10 and 15 -year all cause revision-free device survival specifically in first-time penile implants of $68.5 \%$ and $59.7 \%$, respectively. Revisionfree survival rates relating specifically to device malfunction were found to be $79.4 \%$ and $71.2 \%$ at 10 and 15 years, respectively (56). Improvements in device survival may reflect advances in prosthesis design over time that will continue to reduce malfunction in the future.

\section{Management}

In cases of device malfunction, the prosthesis must be properly inspected, and in the majority of cases, replaced with a new device. Given the challenging and difficult-toaccess location of reservoirs at the time of revision surgery, there is debate regarding whether some or all components of the device must be removed and replaced. It is advisable that, in the case of device malfunction and the need for revision, complete removal of the affected components be undertaken. Infection risk in revision surgery is mitigated through, as discussed previously, meticulous adherence to antisepsis in addition to perioperative antibiotics, washout of the operative field with antibiotic solution, avoidance of skin-to-device contact, and the utilization of an antibioticcoated replacement device (63). Revision surgery is plagued with higher infection rates $(10 \%)$ than virgin implantation $(0-1 \%)$. In the same study, implementation of an antiseptic washout during revision surgery reduced infection rate to $2.45 \%$ (statistically significant reduction). This was accomplished by removal of all device components, including the reservoir (a step that was undertaken in the 


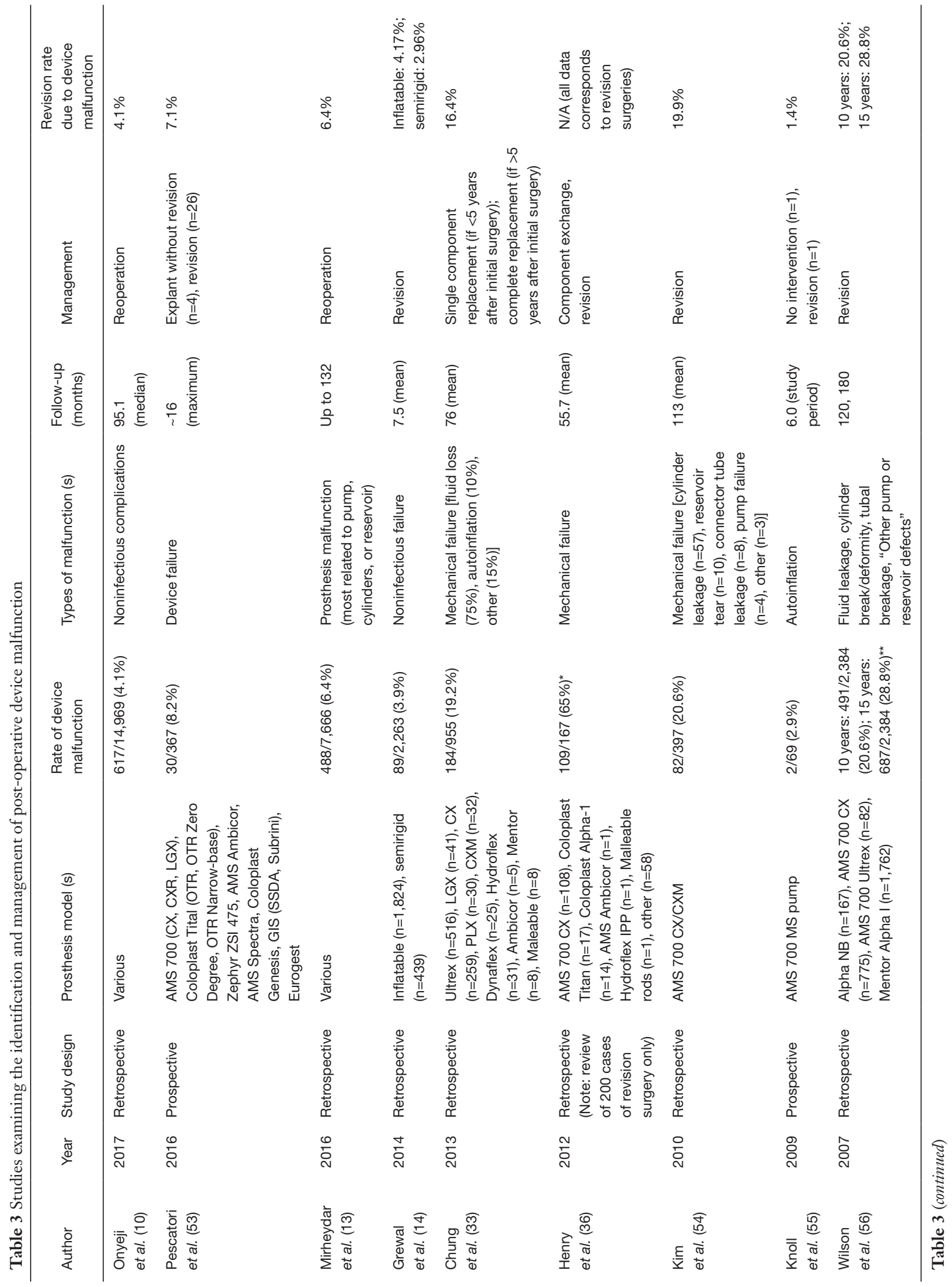




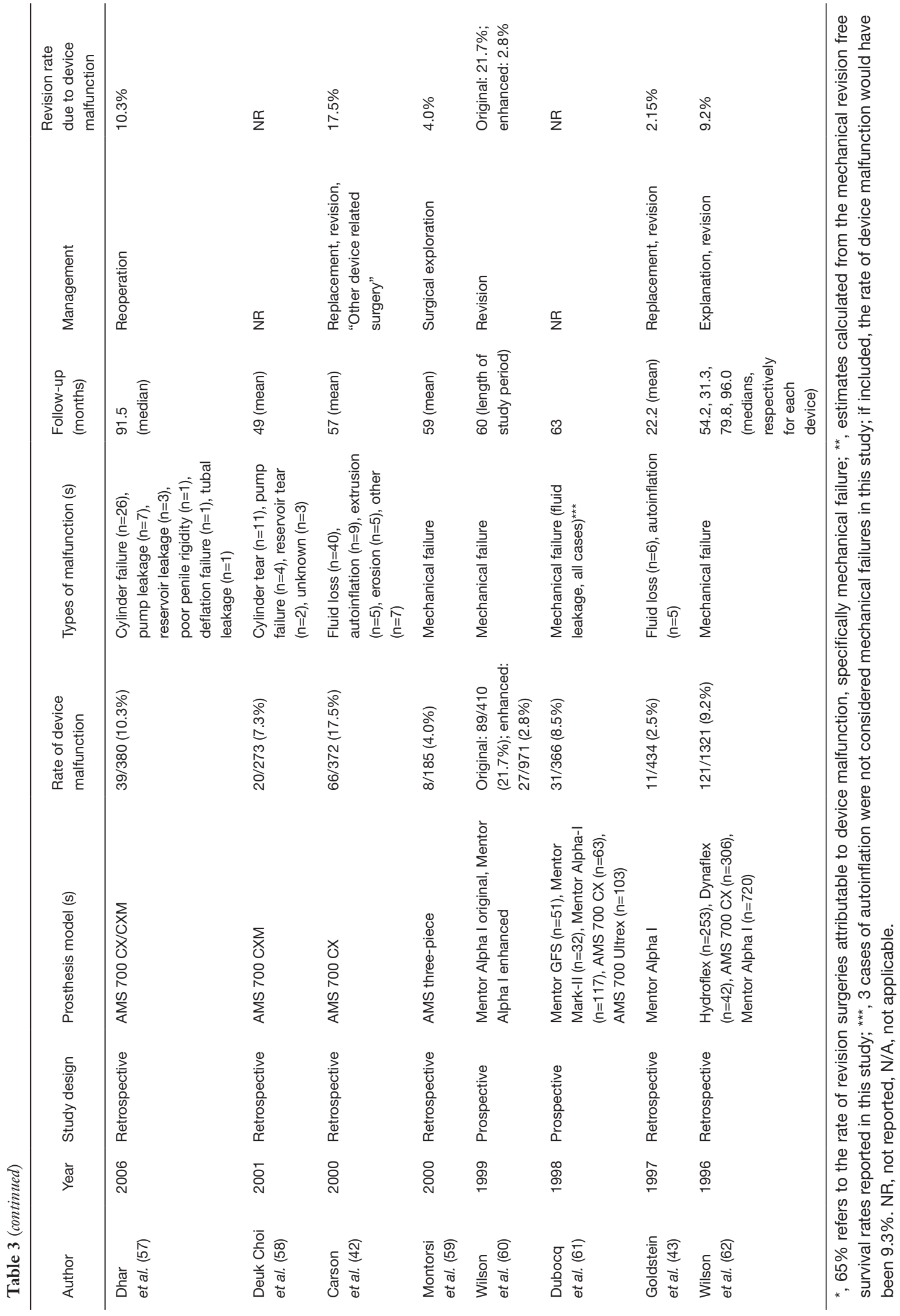


non-washout cohort only if the dissection was facile) (64), and irrigation with half-strength peroxide, half-strength povidone solution, $1 \mathrm{~g}$ vancomycin, and $120 \mathrm{mg}$ gentamicin in $500 \mathrm{~mL}$ of saline. In addition, solutions containing such antibiotics as neosporin, nafcillin/gentamicin, or cephalosporin were utilized (18). Although antibiotic selection varies widely between surgeons (23), it appears that removal of all device components with operative field washout may portend the greatest benefit in preventing post-operative infection following revision surgery for device malfunction.

Several steps may be taken intraoperatively to prevent device malfunction in the immediate and intermediate time course post-operatively. The prosthesis to be implanted should be closely inspected and tested before closing the corporotomy incisions, ensuring functionality and again after pump placement before final incision closure. Correct cylinder size and placement should be assured in order to prevent glans deformities or perforation of corpora, or subsequent erosion. Urethral catheterization prior to reservoir placement is a critical step to mitigate the risk of bladder perforation when the reservoir is placed. Other post-operative complications that can develop include glans bowing [also known as supersonic transport (SST) deformity] or reservoir herniation (51).

Care in placement of the reservoir should be taken in three-piece devices, especially in patients with prior prostatic surgery with associated invasion and manipulation within the space of Retzius. Alternative reservoir placement, including submuscular location, may be reasonable to consider in this context (65). Anatomic changes following robot-assisted laparoscopic prostatectomy (RALP) increase the risk of ectopic reservoir placement (i.e., intraperitoneal cavity) predisposing to bowel injury or obstruction, among other possible consequences (49). Certainly, hematuria, voiding symptoms, or evidence of bowel dysfunction can be evidence of intraperitoneal placement and visceral injuryconsideration of ectopic reservoir location should be a concern (50). Karpman et al. studied alternative reservoir placement in 2015, in accordance with the production of a novel reservoir design by AMS, the "Conceal Low Profile Reservoir." The authors retrospectively reviewed data from the PROPPER study with a specific emphasis on those implanted with AMS 700 concealed $(\mathrm{N}=632)$ and spherical $(\mathrm{N}=127)$ prostheses. A total of $177 / 759(23.3 \%)$ were placed in a submuscular/intrafascial location with the others placed retropubically $(572 / 759,75.4 \%)$ or in another location (10/759, 1.6\%). Five patients were found to have complications related to the reservoir (Table 3), of which 2 had submuscular reservoir placement (2/5, 40\%). Patients with herniation of the reservoir experienced "sharp pain" (6 days post-operatively) and a palpable scrotal mass (21 days post-operatively), respectively. Thus, depending on the mechanical aberration present, patient presentations can be dramatically different in the immediate post-operative period. It should be noted that Karpman et al. were specifically evaluating complications pertaining to the reservoir in their study, which was completed with a goal of providing evidence as to the safety of alternative reservoir placement. The authors noted an overall complication rate of $3.9 \%$ (29 patients with a recorded 35 complications), 5 of which attributed to problems with the reservoir $(0.7 \%)$, and the other patients with unclear etiologies of complications (65).

\section{Discussion}

Although there have been dramatic improvements in prosthesis design and implantation technique over the years to decrease complication rates and improve durability and patient satisfaction, principles in penile prosthesis implantation remain well-established. In this review, we have described identification and management principles of the most common post-operative complications, specifically infection, hematoma, and device malfunction. Historical perspective of penile prosthetic implantation surgery is important along with inclusion of recent modifications to fully recognize the range of complications that may occur along with techniques for surgeons to avoid such issues. Antibiotic coatings and washings, strict adherence to antisepsis, re-gloving, and ensuring limited traffic in and out of the operating room may prevent inoculation of bacteria in the operative field. Meticulous hemostasis should be achieved as bleeding is common from multiple sources and the scrotum is a dependent, pliable organ that will otherwise accommodate a large fluid collection or hematoma. Intraoperative sizing and testing of devices to be placed is important to avoid device malfunction (most commonly due to fluid leak) and ensure proper long-term function.

Post-operative erosion of prosthesis components is an uncommon but devastating complication worth noting. Distal cylinder and scrotal pump erosion is usually related to infection but isolated erosion has been described in the literature (66-70). Impending extrusion of the prosthesis components may be evident with physical examination and can be confirmed if necessary through magnetic 
resonance imaging (MRI). At times, imaging studies may be inconclusive and surgical exploration becomes necessary to confirm the diagnosis and revise the implant (71). Distal cylindrical erosion through the corpus cavernosum with extrusion affecting the urethra, glans, or corporeal shaft can be managed through multiple methods. Options include reseating the cylinders and using fibrotic tissue to support the containment of the cylinders (corporoplasty), utilization of alloplastic materials such as Gortex polytetrafluoroethylene polypropylene mesh (Marlex) to create a "windsock" or utilization of prefabricated autologous fascial grafts $(67,72,73)$. Scrotal pump erosion in IPPs may initially present as a small pustule that rapidly progresses over the course of 2 weeks (68). Management may require complete removal of the entire penile implant but salvage techniques have been described that focus solely on revising the pump $(70,74)$. Furlow and Goldwasser described replacement of eroded pump components with new sterile pumps positioned in the ipsilateral or contralateral hemiscrotum with associated salvage success rates of $67 \%$ and $73 \%$, respectively (70). Köhler et al. replaced eroded inflatable prosthesis components with an AMS 650 semirigid prosthesis as a temporizing bridge therapy. This option prevents the fibrosis of the shaft and allows the scrotum to heal, allowing reimplantation with inflatable prosthesis to be attempted in the future without significant fibrotic hindrance (74).

Glans hypermobility may also be associated with the placement of a penile prosthesis. This is an abnormality which can result when attachments between the corpora cavernosa and the glans penis are loose, possibly due to laxity of the corpora-glans ligament $(75,76)$. The SST deformity can develop as a post-operative complication, resulting in an exaggerated angle present between the glans penis and the penile shaft (75). These two entities have been previously defined under the umbrella term "floppy glans syndrome" but differentiated based on etiology: glans hypermobility being the consequence of anatomical variation among patients which manifests following implantation and SST deformity as the result of utilizing an improperly sized or positioned cylinder leading to inadequate compression of the vasculature from the glans (76). Glans hypermobility and the SST deformity have been reported in variable rates, specifically $5 \%$ and $25 \%$ of patients undergoing penile prosthesis placement $(36,77)$. Management of the SST deformity may include glanulopexy (surgical fixation of the glans), which was studied in 10 patients in a 2001 study. $90 \%$ were satisfied with the outcome, having not experienced damage to the implant nor loss of sensation (78).

Although the majority of studies of penile prosthetic complications are retrospective, these reveal overall generally low rates of complications especially with adherence to standard precautions and protocols.

We have summarized the rates of infection, bleeding/ hematoma formation, and device malfunction in Tables 1-3, respectively. Rates of infection or reoperation due to infection ranged between $0.46 \%$ and $5.3 \%$ (Table 1) (15). While these rates are relatively low overall, infected devices must be explanted and revised using salvage techniques (9). Post-operative hematoma was observed at overall rates between $0.2 \%$ and $3.6 \%$ (Table 2) $(34,43$ ). While no clear consensus is provided regarding closed drainage systems, some have derived benefit from this approach while others cite lack of evidence and added risk of infection as reasons to avoid the utilization of a drain unless there is a particular elevated bleeding risk $(34,45,48)$. The decision to routinely place a drain in penile prosthesis surgery is thus largely a matter of surgeon preference and may not be necessary except in cases of excessive bleeding or patients to be restarting immediate anticoagulation. Overall rates of device malfunction, with a wide spectrum of definitions, ranged from $2.5 \%$ to $28.8 \%$ but the time of follow-up is of critical importance as it is expected that all devices may eventually fail. Accordingly, these rates of device malfunction were derived from studies with follow-up of 22.2 (mean) and 180 months, respectively $(43,56)$. Device malfunction appears to be the most common reason for reoperation over time: in a study by Henry et al., 109/167 cases $(65 \%)$ of revision surgeries occurred due to device mechanical failure (Table 3) (36).

Among studies included in this review, limitations arise from dramatic variation in recorded variables and bias which may occur depending on the data source. For example, the New York SPARCS database utilized by Onyeji et al. did not record data from patients who had a re-operation or prosthesis revision in different states; in addition, data from private surgical centers were not included (10). Varying time courses, follow-up, operative technique, surgeon experience and annual case volume, antibiotic choice, patient-specific variables, prosthetic devices, and variable utilization of closed drains make it difficult to draw direct comparisons and conclusions between these studies.

Reflection on the last several decades of penile prosthesis implantation can provide perspective to assess future directions. Design modifications over time have improved the durability and complication rates attributed to infection. 
With additional modifications to facilitate implantation and reduce infection risk, the penile prosthesis will continue to evolve with improved reliability and durability. In addition to continued modifications of penile prostheses to simplify use for patients, a novel heat-activated prosthesis has been designed and preliminarily tested by Le et al.; perhaps additional biomechanical analysis may provide insight into the technology for future penile implants with decreased risk of complications (79).

\section{Conclusions}

Penile prostheses have revolutionized the treatment of refractory ED since their initial introduction in the 1960s and 1970s. While improvements in design and technique have minimized complications, potential postoperative complications include infection, bleeding/ hematoma formation, and device malfunction. Prompt identification and management of these post-operative complications should be conducted. In the future, advances in penile prosthesis design will likely continue to improve complication rates and device survival. Future studies may focus on the application of novel technology with prospective analysis in larger patient populations and with longer-term follow-up.

\section{Acknowledgements}

None.

\section{Footnote}

Conflicts of Interest: The authors have no conflicts of interest to declare.

\section{References}

1. Lash H, Zimmerman DC, Loeffler RA. Silicone implantation: inlay method. Plast Reconstr Surg 1964;34:75-80.

2. Scott FB, Bradley WE, Timm GW. Management of erectile impotence. Use of implantable inflatable prosthesis. Urology 1973;2:80-2.

3. Bettocchi C, Palumbo F, Spilotros M, et al. Penile prostheses. Ther Adv Urol 2010;2:35-40.

4. Boolell M, Allen M, Ballard S, et al. Sildenafil: an orally active type 5 cyclic GMP-specific phosphodiesterase inhibitor for the treatment of penile erectile dysfunction.
Int J Impot Res 1996;8:47-52.

5. Goldstein I, Lue TF, Padma-Nathan H, et al. Oral sildenafil in the treatment of erectile dysfunction. $\mathrm{N} \mathrm{Engl} \mathrm{J}$ Med 1998;338:1397-404.

6. Hatzimouratidis K, Amar E, Eardley I, et al. Guidelines on male sexual dysfunction: erectile dysfunction and premature ejaculation. Eur Urol 2010;57:804-14.

7. Jarow JP. Risk factors for penile prosthetic infection. J Urol 1996;156:402-4.

8. Goetz A, Yu VL, O'Donnell WF. Surgical complications related to insertion of penile prostheses with emphasis on infection and cost. Infect Control Hosp Epidemiol 1988;9:250-4.

9. Brant MD, Ludlow JK, Mulcahy JJ. The prosthesis salvage operation: immediate replacement of the infected penile prosthesis. J Urol 1996;155:155-7.

10. Onyeji IC, Sui W, Pagano MJ, et al. Impact of Surgeon Case Volume on Reoperation Rates after Inflatable Penile Prosthesis Surgery. J Urol 2017;197:223-9.

11. Antonini G, Busetto GM, De Berardinis E, et al. Minimally invasive infrapubic inflatable penile prosthesis implant for erectile dysfunction: evaluation of efficacy, satisfaction profile and complications. Int J Impot Res 2016;28:4-8.

12. Henry GD, Karpman E, Brant W, et al. The Who, How and What of Real-World Penile Implantation in 2015: The PROPPER Registry Baseline Data. J Urol 2016;195:427-33.

13. Mirheydar H, Zhou T, Chang DC, et al. Reoperation Rates for Penile Prosthetic Surgery. J Sex Med 2016;13:129-33.

14. Grewal S, Vetter J, Brandes SB, et al. A population-based analysis of contemporary rates of reoperation for penile prosthesis procedures. Urology 2014;84:112-6.

15. Eid JF, Wilson SK, Cleves M, et al. Coated implants and "no touch" surgical technique decreases risk of infection in inflatable penile prosthesis implantation to $0.46 \%$. Urology 2012;79:1310-5.

16. Mulcahy JJ, Carson CC 3rd. Long-term infection rates in diabetic patients implanted with antibiotic-impregnated versus nonimpregnated inflatable penile prostheses: 7-year outcomes. Eur Urol 2011;60:167-72.

17. Carson CC 3rd, Mulcahy JJ, Harsch MR. Long-term infection outcomes after original antibiotic impregnated inflatable penile prosthesis implants: up to 7.7 years of followup. J Urol 2011;185:614-8.

18. Wilson SK, Zumbe J, Henry GD, et al. Infection reduction using antibiotic-coated inflatable penile prosthesis. 
Urology 2007;70:337-40.

19. Wolter CE, Hellstrom WJ. The hydrophilic-coated inflatable penile prosthesis: 1-year experience. J Sex Med 2004;1:221-4.

20. Carson CC 3rd. Efficacy of antibiotic impregnation of inflatable penile prostheses in decreasing infection in original implants. J Urol 2004;171:1611-4.

21. Mulhall JP, Bloom K. Comparison of in-patient and out-patient penile prosthesis surgery. Int J Impot Res 2001;13:251-4.

22. Dhabuwala C, Sheth S, Zamzow B. Infection rates of rifampin/gentamicin-coated Titan Coloplast penile implants. Comparison with Inhibizone-impregnated AMS penile implants. J Sex Med 2011;8:315-20.

23. Wosnitzer MS, Greenfield JM. Antibiotic patterns with inflatable penile prosthesis insertion. J Sex Med 2011;8:1521-8.

24. Wolf JS Jr, Bennett CJ, Dmochowski RR, et al. Best practice policy statement on urologic surgery antimicrobial prophylaxis. J Urol 2008;179:1379-90.

25. Droggin D, Shabsigh R, Anastasiadis AG. Antibiotic coating reduces penile prosthesis infection. J Sex Med 2005;2:565-8.

26. Abouassaly R, Angermeier KW, Montague DK. Risk of infection with an antibiotic coated penile prosthesis at device replacement for mechanical failure. J Urol 2006;176:2471-3.

27. Bettocchi C, Ditonno P, Palumbo F, et al. Penile prosthesis: what should we do about complications? Adv Urol 2008:573560.

28. Singer M, Deutschman CS, Seymour CW, et al. The Third International Consensus Definitions for Sepsis and Septic Shock (Sepsis-3). Jama 2016;315:801-10.

29. Droller MJ, Scott, FB, Selim, AM. Rescue procedure: an alternative to complete removal for treatment of infected penile prosthesis [Abstract 396]. J Urol 1987;137:202.

30. Mulcahy JJ. Long-term experience with salvage of infected penile implants. J Urol 2000;163:481-2.

31. Mellon MJ, Broghammer JR, Henry GD. The Mulcahy Salvage: Past and Present Innovations. J Sex Med 2015;12 Suppl 7:432-6.

32. Montague DK. Penile prosthesis corporotomy closure: a new technique. J Urol 1993;150:924-5.

33. Chung E, Van CT, Wilson I, et al. Penile prosthesis implantation for the treatment for male erectile dysfunction: clinical outcomes and lessons learnt after 955 procedures. World J Urol 2013;31:591-5.

34. Pozza D, Pozza M, Musy M, et al. 500 penile prostheses implanted by a surgeon in Italy in the last 30 years. Arch Ital Urol Androl 2015;87:216-21.

35. Holloway FB, Farah RN. Intermediate term assessment of the reliability, function and patient satisfaction with the AMS700 Ultrex penile prosthesis. J Urol 1997;157:1687-91.

36. Henry GD, Donatucci CF, Conners W, et al. An outcomes analysis of over 200 revision surgeries for penile prosthesis implantation: a multicenter study. J Sex Med 2012;9:309-15.

37. Sadeghi-Nejad H, Ilbeigi P, Wilson SK, et al. Multiinstitutional outcome study on the efficacy of closedsuction drainage of the scrotum in three-piece inflatable penile prosthesis surgery. Int J Impot Res 2005; 17:535-8.

38. Garber BB, Bickell M. Delayed postoperative hematoma formation after inflatable penile prosthesis implantation. J Sex Med 2015;12:265-9.

39. Natali A, Olianas R, Fisch M. Penile implantation in Europe: successes and complications with 253 implants in Italy and Germany. J Sex Med 2008;5:1503-12.

40. Minervini A, Ralph DJ, Pryor JP. Outcome of penile prosthesis implantation for treating erectile dysfunction: experience with 504 procedures. BJU Int 2006;97:129-33.

41. Levine LA, Estrada CR, Morgentaler A. Mechanical reliability and safety of, and patient satisfaction with the Ambicor inflatable penile prosthesis: results of a 2 center study. J Urol 2001;166:932-7.

42. Carson CC, Mulcahy JJ, Govier FE. Efficacy, safety and patient satisfaction outcomes of the AMS 700CX inflatable penile prosthesis: results of a long-term multicenter study. AMS 700CX Study Group. J Urol 2000;164:376-80.

43. Goldstein I, Newman L, Baum N, et al. Safety and efficacy outcome of mentor alpha-1 inflatable penile prosthesis implantation for impotence treatment. J Urol 1997;157:833-9.

44. Wilson SC, Delk JI. Hematoma formation following penile prosthesis implantation: To drain or not to drain. J Urol 1996;55:634A.

45. Kramer A, Goldmark E, Greenfield J. Is a closed-suction drain advantageous for penile implant surgery? The debate continues. J Sex Med 2011;8:601-6.

46. Henry GD, Wilson SK. Updates in inflatable penile prostheses. Urol Clin North Am 2007;34:535-47, vi.

47. Wilson SK, Henry GD. Penoscrotal approach for threepiece and two-piece hydraulic penile implants. Urol Clin North Am 2002;10:169-80.

48. Köhler TS, Hellstrom WJ. Using wound drains for the uncomplicated penile prosthesis. J Urol 2011;186:1187-9.

49. Sadeghi-Nejad H, Munarriz R, Shah N. Intra-abdominal reservoir placement during penile prosthesis surgery in 
post-robotically assisted laparoscopic radical prostatectomy patients: a case report and practical considerations. J Sex Med 2011;8:1547-50.

50. Levine LA, Hoeh MP. Review of penile prosthetic reservoir: complications and presentation of a modified reservoir placement technique. J Sex Med 2012;9:2759-69.

51. Sadeghi-Nejad H. Penile prosthesis surgery: a review of prosthetic devices and associated complications. J Sex Med 2007;4:296-309.

52. Trost L, Wanzek P, Bailey G. A practical overview of considerations for penile prosthesis placement. Nat Rev Urol 2016;13:33-46.

53. Pescatori E, Alei G, Antonini G, et al. INSIST-ED: Italian Society of Andrology registry on penile prosthesis surgery. First data analysis. Arch Ital Urol Androl 2016;88:122-7.

54. Kim DS, Yang KM, Chung HJ, et al. AMS 700CX/CXM inflatable penile prosthesis has high mechanical reliability at long-term follow-up. J Sex Med 2010;7:2602-7.

55. Knoll LD, Henry G, Culkin D, et al. Physician and patient satisfaction with the new AMS 700 momentary squeeze inflatable penile prosthesis. J Sex Med 2009;6:1773-8.

56. Wilson SK, Delk JR, Salem EA, et al. Long-term survival of inflatable penile prostheses: single surgical group experience with 2,384 first-time implants spanning two decades. J Sex Med 2007;4:1074-9.

57. Dhar NB, Angermeier KW, Montague DK. Long-term mechanical reliability of AMS 700CX/CXM inflatable penile prosthesis. J Urol 2006;176:2599-601; discussion 601.

58. Deuk Choi Y, Jin Choi Y, Hwan Kim J, et al. Mechanical reliability of the AMS 700CXM inflatable penile prosthesis for the treatment of male erectile dysfunction. J Urol 2001;165:822-4.

59. Montorsi F, Rigatti P, Carmignani G, et al. AMS threepiece inflatable implants for erectile dysfunction: a longterm multi-institutional study in 200 consecutive patients. Eur Urol 2000;37:50-5.

60. Wilson SK, Cleves MA, Delk JR 2nd. Comparison of mechanical reliability of original and enhanced Mentor Alpha I penile prosthesis. J Urol 1999;162:715-8.

61. Dubocq F, Tefilli MV, Gheiler EL, et al. Long-term mechanical reliability of multicomponent inflatable penile prosthesis: comparison of device survival. Urology 1998;52:277-81.

62. Wilson SK, Cleves M, Delk JR 2nd. Long-term results with Hydroflex and Dynaflex penile prostheses: device survival comparison to multicomponent inflatables. J Urol 1996;155:1621-3.

63. Hinds PR, Wilson SK, Sadeghi-Nejad H. Dilemmas of inflatable penile prosthesis revision surgery: what practices achieve the best outcomes and the lowest infection rates? (CME). J Sex Med 2012;9:2483-91; quiz 92.

64. Rajpurkar A, Bianco FF Jr., Al-Omar O, et al. Fate of the retained reservoir after replacement of 3-piece penile prosthesis. J Urol 2004;172:664-6.

65. Karpman E, Brant WO, Kansas B, et al. Reservoir alternate surgical implantation technique: preliminary outcomes of initial PROPPER study of low profile or spherical reservoir implantation in submuscular location or traditional prevesical space. J Urol 2015;193:239-44.

66. Talib RA, Shamsodini A, Salem EA, et al. Isolated pump erosion of an inflatable penile prosthesis through the scrotum in a diabetic patient. Arch Ital Urol Androl 2013;85:53-5.

67. Mulcahy JJ. Distal corporoplasty for lateral extrusion of penile prosthesis cylinders. J Urol 1999;161:193-5.

68. Sawczuk I, Wechsler M. Erosion of the pump mechanism of an inflatable penile prosthesis through the scrotum in a diabetic patient. J Natl Med Assoc 1985;77:577-8.

69. Levine LA, Benson J, Hoover C. Inflatable penile prosthesis placement in men with Peyronie's disease and drug-resistant erectile dysfunction: A single-center study. J Sex Med 2010;7:3775-83.

70. Furlow WL, Goldwasser B. Salvage of the eroded inflatable penile prosthesis: a new concept. J Urol 1987;138:312-4.

71. McPhail EF, Nehra A, Bruner BC, et al. MRI and its role in the evaluation and surgical decision making in patients with challenging IPP presentations: descriptions of MRI findings and algorithm for patient management. BJU Int 2012;109:1848-52.

72. Carson CC, Noh CH. Distal penile prosthesis extrusion: treatment with distal corporoplasty or Gortex windsock reinforcement. Int J Impot Res 2002;14:81-4.

73. Alter GJ, Greisman J, Werthman PE, et al. Use of a prefabricated tunica vaginalis fascia flap to reconstruct the tunica albuginea after recurrent penile prosthesis extrusion. J Urol 1998;159:128-32.

74. Köhler TS, Modder JK, Dupree JM, et al. Malleable implant substitution for the management of penile prosthesis pump erosion: a pilot study. J Sex Med 2009;6:1474-8.

75. Ball TP Jr. Surgical repair of penile "SST" deformity. Urology 1980;15:603-4.

76. Bickell M, Manimala N, Parker J, et al. Floppy Glans Syndrome: Pathogenesis and Treatment. Sex Med Rev 
2016;4:149-56.

77. Morey AF. Reconstructing penile supersonic transporter (SST) deformity using glanulopexy (glans fixation). J Urol 2005;174:969.

78. Mulhall JP, Kim FJ. Reconstructing penile supersonic

Cite this article as: O'Rourke TK Jr, Erbella A, Zhang Y, Wosnitzer MS. Prevention, identification, and management of post-operative penile implant complications of infection, hematoma, and device malfunction. Transl Androl Urol 2017;6(Suppl 5):S832-S848. doi: 10.21037/tau.2017.06.07 transporter (SST) deformity using glanulopexy (glans fixation). Urology 2001;57:1160-2.

79. Le B, McVary K, McKenna K, et al. A Novel Thermalactivated Shape Memory Penile Prosthesis: Comparative Mechanical Testing. Urology 2017;99:136-41. 